\title{
Development of self-nanoemulsifying tablet (SNET) for bioavailability enhancement of sertraline
}

\author{
Mohammad Akhlaquer Rahman',2,*, Mohammad Mujahid ${ }^{1}$ \\ ${ }^{1}$ Faculty of Pharmacy, Integral University, Kursi Road, Lucknow, India, ${ }^{2}$ College of Pharmacy, Taif University, Taif, KSA
}

\begin{abstract}
The purpose of the study was to combine the advantages of self-nanoemulsifying drug delivery systems and tablets as a conventional dosage form. Self-nanoemulsifying drug delivery system (SNEDDS) was prepared to enhance the solubility and thus oral bioavailability of sertraline. Aqueous titration method was used to prepare the liquid SNEDDS; ternary phase diagrams were constructed and based on smaller droplet size $(24.8 \mathrm{~nm})$, minimum viscosity $(153.63 \mathrm{cP})$ and polydispersity index $(0.182)$, higher percentage transmittance (95\%) and in vitro drug release (97\%), an optimum system was designated. Liquid SNEDDS was transformed into free-flowing powder by solid adsorption technique followed by compression into tablets. In vitro release of sertraline from liquid and solid SNEDDS was found to be highly significant compared to plain sertraline $(\mathrm{p}<0.01)$. Pharmacokinetic studies after oral administration of liquid and solid SNEDDS in rats showed about 6-and 5-fold increased absorption of sertraline compared to the aqueous suspension of sertraline. These studies demonstrate that the solid SNEDDS are promising strategies for successful delivery of poorly water-soluble drug like sertraline.
\end{abstract}

Keywords: SNEDDS. Phase diagrams. Solubility. Thermodynamic stability. Oral delivery. Bioavailability

\section{INTRODUCTION}

Sertraline (SRT) free base (Figure 1) is lipophilic (log $\mathrm{P}, 5.1)$, poorly water-soluble drug $(3.5 \mathrm{mg} / \mathrm{L})$ belonging to the category "Selective Serotonin Reuptake Inhibitors (SSRIs)" commercially available as hydrochloride salt with around $44 \%$ oral bioavailability. Sertraline was found to be safer than other SSRIs, work better than fluoxetine for some subtypes of depression (Flament et al., 1999), reported as most prescribed antidepressant in U.S. retail market in 2007. Modification of the physicochemical properties such as salt formation of the compound is in practice as one of the approach to improve the dissolution rate of such drugs. But in general, these methods have their own limitations. For instance, salt formation of neutral compound is not feasible, and the synthesis of weak acid and weak base salts may not always be practical. Moreover, the salts that are formed may convert back to their original acid or base forms leading to aggregation in the gastrointestinal tract (GIT) leads to slow/poor absorption

\footnotetext{
*Correspondence: A. Rahman. Faculty of Pharmacy, Integral University, Kursi Road, Lucknow-226026 (India). Phone: +91-9565402042. E-mail: rahmanpharma@gmail.com
}

(Serajuddin, 1999). This may be the possible reason for poor oral bioavailability of sertraline hydrochloride. Also, the salt formation needs extra expenditure of revenue in the form of processing cost.<smiles>CN[C@H]1CC[C@H](c2ccc(Cl)c(Cl)c2)c2ccccc21</smiles>

FIGURE 1 - Chemical structure of sertralin free base.

Scientific attention has been made in recent years on lipid-based formulations to improve oral bioavailability of poorly water-soluble drug compounds (Humberstone, Charman, 1997). The most popular approach is the incorporation of the active constituents into inert lipid vehicles such as oils, surfactant and surfactant dispersions (Nielsen, Petersen, Ilertz, 2008), liposomes (Schwendener, Schott, 1996), emulsions (Kararli et al., 1992), self- 
emulsifying (Pouton, 1997) and self-microemulsifying formulations (Shen, Zhong, 2006) with particular emphasis on self-nanoemulsifying drug delivery systems (Gursoya, Benita, 2004). SNEDDS comprises of isotropic mixtures of natural, semisynthetic or synthetic oils with surfactants usually with one or more hydrophilic cosolvents or co-emulsifiers. These systems spontaneously emulsify when diluted to gastrointestinal fluids to form oil-in-water $(\mathrm{o} / \mathrm{w})$ nanoemulsion having droplet size less than $100 \mathrm{~nm}$ (Mou et al., 2008; Porter et al., 2008). Furthermore, SNEDDS would be an efficient, convenient and more patient compliant approach in comparison to $\mathrm{o} / \mathrm{w}$ nanoemulsion, as SNEDDS can be filled in hard gelatin capsules due to their anhydrous nature enabling its administration as unit dosage form (Date, Nagarsenker, 2007; Rao, Shao, 2008).

Generally, SNEDDS are either administered as liquid dosage forms, encapsulated either in hard or soft gelatin capsules, transformed into granules/pellets and finally into tablets. Lipid formulations however may interact with the capsule shell resulting in either brittleness or softness of the shell. To address this limitation, liquid lipid formulations can be transformed into free-flowing powder by loading the formulation on a suitable solid carrier/transformed into granules/pellets (Rahman et al., 2011). SNEDDS loaded powder/granules/pellets, however should have acceptable flow properties to facilitate capsule or tablet manufacturing in order to pass compendial limit for content uniformity and weight variation. It is a fact that solid dosage forms are preferred more than liquid preparations for many reasons including: facility of manufacturing process, convenience to the patient, dose accuracy, and stability. Incorporation of lipid formulations into solid dosage forms combines the advantages of lipid based drug delivery systems with those of solid dosage forms thus overcoming the drawbacks of lipid formulations (Abbaspour, Makhmalzadeh, 2014; Rashid et al., 2015).

Thus, the objective of the present study was to develop and characterize an optimal stable solid SNEDDS of sertraline using minimum surfactant concentration, so that nano-sized droplets could be maintained on dilution by the gastrointestinal (GI) fluids with an aim to increase its oral bioavailability.

\section{MATERIAL AND METHODS}

\section{Material}

Sertraline was received as gift sample from R\&D division, Ranbaxy, Gurgaon, India. Lauroglycol ${ }^{\mathrm{TM}} 90$
(Propylene glycol monolaurate Type II; monoesters > $90 \%$, C12 (lauric acid) > 95\%), Labrafil ${ }^{\circledR}$ M 2125 CS (Linoleoyl polyoxyl-6 glycerides; Oleic (C18:1) 24-34\%, Linoleic (C18:2) 53-63\%), Maisine ${ }^{\mathrm{TM}} 35-1$ (Glyceryl monolinoleate; C18:2 >50\%; C18:1 10-35\%; C18:0 $<6 \%$; C16 4-20\%) were obtained from Gattefosse Corp. (France). Polyoxy 40 hydrogenated castor oil (Cremophor RH40) and polyoxy-35 castor oil (Cremophor EL) was obtained from BASF Co. (India). Sodium Starch Glycolate was obtained from Thomas baker (Mumbai, India). Magnesium stearate was obtained from Loba Chemie Pvt Ltd, (Mumbai, India). Transparent empty hard gelatin capsules were obtained as gift sample from Associated Capsules Ltd. (Mumbai, India). Other chemicals were of HPLC or analytical grade.

\section{Methods}

\section{Solubility studies}

The solubility of sertraline was ascertained in oils, surfactants and cosurfactants. An excess amount of sertraline was added to $2 \mathrm{~mL}$ of selected lipophile separately in stoppered vials and mixed with the help of vortex mixer. The vials were kept at $30^{\circ} \mathrm{C}$ in an isothermal shaker (Nirmal International, Delhi, India) for 48 hours to reach equilibrium and then centrifuged at $3000 \mathrm{rpm}$ for 10 minutes. The supernatant was filtered through $0.22 \mu \mathrm{m}$ filter for analysis of sertraline.

\section{HPLC analysis of sertraline in vitro and in vivo}

The solubility of sertraline in various excipients was determined by a validated in-house HPLC method. The apparatus consisted of Shimadzu model equipped with quaternary LC-10AVP pumps, variable wavelength programmable UV/VIS detector, SPD-10AVP column oven (Shimadzu), SCL 10AVP system controller (Shimadzu), Rheodyne injector fitted with a $20 \mu \mathrm{L}$ loop and Class-VP 5.032 software. Mobile phase consisted of methanol/phosphate buffer $(70: 30 \% \mathrm{v} / \mathrm{v})$ at $1.25 \mathrm{~mL} / \mathrm{min}$ flow rate, detection at $273 \mathrm{~nm}$ with retention time at 7.05 min. The same method was used to quantify dissolution samples and amount of sertraline in plasma after oral administration of optimized formulations and aqueous suspension of plain drug.

\section{Preliminary screening of surfactant and cosurfactant}

For the screening of suitable surfactant, emulsification ability was determined according to the method described (Date, Nagarsenker, 2007). Briefly, a fixed amount of Labrasol, Cremophor RH40, Cremophor EL, and Acconon CC- 6 were mixed with the same 
quantity of the oily phase. The mixtures were gently heated at $50{ }^{\circ} \mathrm{C}$ in water bath for homogenization of the components. Each mixture, $25 \mathrm{mg}$ was then diluted with distilled water to $25 \mathrm{~mL}$ in a stoppered conical flask. Ease of emulsification was judged by the number of flask inversions required to yield homogenous emulsion. Emulsions were allowed to stand for $12 \mathrm{~h}$ and their \% transmittance was evaluated by UV spectrophotometer using distilled water as a blank. Emulsions were furthermore observed visually for any turbidity or phase separation. The selected oily phase and surfactant were used for further screening of the different cosurfactants (Lauroglycol 90, Lauroglycol FCC, Caproyl 90, propylene glycol and polyethylene glycol) for their emulsification ability. Mixtures of $50 \mathrm{mg}$ of cosurfactant, $100 \mathrm{mg}$ surfactant, and $200 \mathrm{mg}$ oil were prepared and evaluated in a similar fashion as described above.

\section{Construction of ternary phase diagram}

On the basis of the solubility study Labrafil M 2125 CS [(LBF M 2125 CS ) + Maisine 35-1)] in 1:1 ratio was selected as the oil phase. Labrasol and CremophorEL were used as surfactants and Lauroglycol 90 as cosurfactant. Surfactant and cosurfactant $\left(\mathrm{S}_{\text {mix }}\right)$ in each group were mixed in different volume ratios (1:0, 1:1, $1: 2,1: 3,2: 1,3: 1,4: 1)$. These $S_{\text {mix }}$ ratios were chosen in increasing concentration of cosurfactant with respect to surfactant and increasing concentration of surfactant with respect to cosurfactant for detailed study of the phase diagrams in nanoemulsion formation.

For each phase diagram, oil and specific $\mathrm{S}_{\text {mix }}$ ratio were mixed thoroughly in different volume ratios from 1:9 to 9:1 in different glass vials. Sixteen different combinations of oil and $\mathrm{S}_{\text {mix }}[1: 9,1: 8,1: 7,1: 6,1: 5,2: 8$ (1:4), 1:3.5, 1:3, 3:7 (1:2.3), 1:2, 4:6 (1:1.5), 5:5 (1:1), 6:4 (1:0.7), 7:3 (1:0.43), 8:2(1:0.25) and 9:1 (1:0.1)] were made so that maximum ratios were covered to delineate the boundaries of phases precisely formed in the phase diagrams. Pseudo-ternary phase diagrams were developed using aqueous titration method. Slow titration with aqueous phase was done to each volume ratio of oil and $\mathrm{S}_{\text {mix }}$ and visual observation was carried out for transparent and easily flowable o/w nanoemulsions. The physical state of the nanoemulsion was marked on a pseudo-threecomponent phase diagram with one axis representing aqueous phase, the other representing oil and the third representing a mixture of surfactant and cosurfactant at fixed volume ratios $\left(\mathrm{S}_{\text {mix }}\right.$ ratio). From each phase diagram constructed, different formulations were selected from the nanoemulsion region so that single dose of drug could be easily incorporated into the oil phase.

\section{Thermodynamic stability studies}

To overcome the problem of metastable formulation, thermodynamic stability tests were performed by reported method (Shafiq et al., 2007a). Formulations were subjected to six cycles between refrigerator temperature $\left(4{ }^{\circ} \mathrm{C}\right)$ and $40^{\circ} \mathrm{C}$ with storage at each temperature of not less than 48 hours. Formulations which were stable at these temperatures were subjected to centrifugation test at 3500 rpm for $30 \mathrm{~min}$. Formulations that did not show any phase separation were again subjected to freeze thaw stress test between the temperature $-21{ }^{\circ} \mathrm{C}$ and $+25^{\circ} \mathrm{C}$.

\section{Dispersibility test}

The efficiency of self-emulsification was assessed using a standard USP XXII dissolution apparatus 2 (Khoo et al., 1998). $1 \mathrm{~mL}$ of each formulation was added to 500 $\mathrm{mL}$ of distilled water, $0.1 \mathrm{~N} \mathrm{HCl}$ and 6.8 phosphate buffers (PB) at $37 \pm 0.5^{\circ} \mathrm{C}$. A standard stainless-steel dissolution paddle rotating at $50 \mathrm{rpm}$ provided gentle agitation. The in vitro performances of the formulations were visually assessed using the following grading system (Khoo et al., 1998, Shafiq et al., 2007b). A, denoting a rapidly forming (within $1 \mathrm{~min}$ ) nanoemulsion which was clear or slightly bluish in appearance; $\mathrm{B}$, denoting a rapidly forming, slightly less clear emulsion which had a bluish white appearance; $\mathrm{C}$, denoting a bright white emulsion (similar in appearance to milk) that formed within $2 \mathrm{~min}$; $\mathrm{D}$, denoting a dull, grayish white emulsion with a slightly oily appearance that was slow to emulsify (longer than 2 $\mathrm{min}$ ); and E, denoting a formulation which exhibited either poor or minimal emulsification with large oil droplets present on the surface.

\section{Incorporation of drug in placebo formulations}

From each group separately, one formulation was selected from each percent of oil $(10,15,20$ and $25 \%)$, having the least $\mathrm{S}_{\text {mix }}$ concentration irrespective of $\mathrm{S}_{\text {mix }}$ ratio used, but passing dispersebility test in Grade $A$ or B only. $0.5 \mathrm{~mL}$ of formulation was prepared so that it can be easily filled into size \#0 capsule. Formulation containing $10 \%$ of oil was excluded from the study because it just dissolves single dose of drug (i.e. 25 $\mathrm{mg}$ ) which is equal to the saturation solubility. $25 \mathrm{mg}$ of sertraline was incorporated in each placebo formulation of oil mixture and respective $S_{\text {mix }}$ ratio and mixed with the help of vortex mixer.

Interim stability study: Interim stability studies were carried out by keeping the sertraline incorporated formulations at $40{ }^{\circ} \mathrm{C} / 75 \% \mathrm{RH}$. Physical appearance (precipitation or phase separation) was observed after 1 month. 


\section{Cloud point measurement}

Developed SNEDDS were compared for cloud point value. Each formulation was diluted with water in the ratio of 1:100 and placed in a water bath with gradual increase in temperature. At the cloud point, the drop in sample $\%$ transmittance from the zero point was measured spectrophotometrically (Zhang et al., 2008).

\section{Percentage transmittance}

The optical clarity of SNEDDS formulations was measured spectroscopically upon dilution. Percentage transmittance was determined using Shimadzu UV spectrophotometer (Shimadzu, Japan). Formulations containing $25 \mathrm{mg}$ of sertraline was diluted 100 times using double distilled water and analyzed at $500 \mathrm{~nm}$.

\section{Viscosity determination}

The viscosity of the formulations $(0.5 \mathrm{~g})$ was determined without dilution using a Brookfield DV III ultra V6.0 RV cone and plate rheometer (Brookfield Engineering Laboratories, Inc, Middleboro, MA, spindle \# CPE40) was used to determine the viscosity of developed formulations at $25 \pm 1.0^{\circ} \mathrm{C}$. The software used for the calculations was Rheocalc V2.6.

\section{Droplet size and polydispersity index}

The average droplet size and polydispersity index (PDI) of SNEDDS were measured by photon correlation spectroscopy (PCS) using a Malvern Zetasizer (Nano ZS90, Malvern instruments Ltd., UK) with a $50 \mathrm{mV}$ laser. The sensitivity range was $10 \mathrm{~nm}$ to $5 \mu \mathrm{m}$ and the data were shown by computer calculation using the Mie equations of light scattering. The measurements were performed at $25^{\circ} \mathrm{C}$ at a fixed angle of $90^{\circ}$. The formulation $(0.1 \mathrm{~mL})$ was dispersed in $100 \mathrm{~mL}$ of water under gentle stirring in a glass beaker. $1 \mathrm{~mL}$ aliquot was withdrawn and added into a sample cell for droplet size measurement.

\section{In vitro release study}

The in vitro release study was performed for the following objectives: to evaluate the sertraline release characteristic from developed SNEDDS and to compare the release relative to the plain sertraline. The studies were performed using dissolution apparatus II USP (DS 8000, Labindia, India) filled with $900 \mathrm{~mL}$ simulated gastric fluid (pH 1.2, without enzymes) as a dissolution media. The temperature was set at $37 \pm 0.5^{\circ} \mathrm{C}$ and speed of the paddle was maintained at $100 \mathrm{rpm} .5 \mathrm{~mL}$ of the samples were drawn out at the predetermined intervals and the same volume of fresh dissolution media was replenished. The samples were filtered through $0.22 \mu \mathrm{m}$ Millipore filters and analyzed using validated in-house HPLC method and quantified as percentage using the following equation:

$\%$ drug release $=\frac{\text { Amount of drug in releasing medium }}{\text { Total amount of drug }} \times 100$

\section{Development of solid SNEDDS}

\section{Adsorption on solid carriers}

The liquid SNEDDS was prepared by dissolving 25 $\mathrm{mg}$ of sertraline in oils and mixing the required amounts of surfactant and cosurfactant using vortex mixer. Optimized liquid SNEDDS was then mixed with solid carriers (dibasic calcium phosphate, anhydrous lactose, calcium carbonate, magnesium carbonate and Aerosil 200) in different ratios $(2: 1,1: 1$ and $1: 2)$ by adding dropwise over it placed in a beaker. After each addition, the mixture was homogenized using glass rod to ensure uniform distribution of the droplet. The solid formulations obtained were passed through sieve number 22 to achieve uniformly free flowing self-nanoemulsifying granules (SNEG's). The final blend of SNEG's along with sodium starch glycolate $(5 \%)$ and magnesium stearate $(1 \%)$ were evaluated for various micromeritic properties viz. bulk density, tapped density, angle of repose, Carr's Index and Hausner's ratio. The final blend was compressed into tablet using single punch rotary compression machine; flat faced and die sized $10 \mathrm{~mm}$ punch were used.

\section{Droplet size and polydispersity index of reconstituted nanoemulsion}

Solid SNEDDS (100 mg) prepared were dispersed with $10 \mathrm{ml}$ distilled water by vortex mixing and then incubated at $25^{\circ} \mathrm{C}$. Droplet size and polydispersity index of reconstituted nanoemulsion was assessed by photon correlation spectroscopy (Zetasizer 1000 HS, Malvern Instruments, UK). Light scattering was monitored at $25^{\circ} \mathrm{C}$ at $90^{\circ}$ angle.

\section{$X$-ray powder diffraction study}

To verify the physical state of sertraline in solid SNEDDS, X-ray powder scattering measurements was carried out. A voltage of $40 \mathrm{kV}$ and a current of $40 \mathrm{~mA}$ for the generator applied with $\mathrm{Cu}$ as the tube anode material. The solids exposed to a $\mathrm{Cu}-\mathrm{K}$ radiation, over a range of $2 \theta$ angles from $10-40^{\circ}$, at an angular speed of $2^{\circ}(2 \theta) / \mathrm{min}$, a sampling interval of $0.02^{\circ} /$ second.

\section{In vivo study}

Approval to carry out in vivo study was obtained from Institutional animal ethics committee, Faculty of 
Pharmacy, Integral University, and their guidelines were followed. The animals used for in vivo experiments were adult Sprague Dawley rats (SD rats) obtained from Central Drug Research Institute (CDRI), Lucknow, India.

The animals were kept under standard laboratory conditions, temperature at $25 \pm 2{ }^{\circ} \mathrm{C}$ and relative humidity $(55 \pm 5 \%)$. The animals were housed in polypropylene cages, six per cage, with free access to standard laboratory diet and water. The formulations (LF3, powder blend of solid SNEDDS and plain sertraline) were given orally using oral feeding gauge. Dose for the rats was calculated based on the weight of the rats $(2.25 \mathrm{mg}$ of sertraline per $\mathrm{kg}$ body weight) according to the surface area ratio. The rats were anesthetized using ether and blood samples $(0.5 \mathrm{~mL})$ were withdrawn from the tail vein of rat at 0 (pre-dose), $0.5,1,2,4,6,8,12,24$ and $36 \mathrm{~h}$ in microcentrifuge tubes in which $8 \mathrm{mg}$ of EDTA was added as an anticoagulant. The blood collected was mixed with the anticoagulant properly and centrifuged at $5000 \mathrm{rpm}$ for $20 \mathrm{~min}$. The plasma was separated and stored at $-21^{\circ} \mathrm{C}$ until drug analysis.

\section{Pharmacokinetic and statistical analysis}

Pharmacokinetic parameters were calculated by noncompartmental analysis also called as Model independent analysis using WinNonLin version 4.0 (Pharsight Corp., Mountain View, CA). Maximum concentration $\left(\mathrm{C}_{\max }\right)$ and time to reach maximum concentration $\left(\mathrm{T}_{\max }\right)$ are the values obtained directly from concentration-time curve. Area under the concentrationtime curve $\left(\mathrm{AUC}_{0 \rightarrow t}\right)$ was also determined.

\section{RESULTS AND DISCUSSION}

\section{Solubility studies and selection of excipients}

The solubility of sertraline was assessed in different oily phases alone and in combination, surfactant and cosurfactant (Figure 2). The solubility of the lipophilic drug sertraline was found to be highest in the combination of Labrafil M 2125 CS and Maisine 35-1 (1:1) ratio.
Surfactants (Labrasol, Cremophor EL, Cremophor RH40 and Acconon CC-6) had been selected for the study and solubility of sertraline was determined by the described method. Also, the surfactants were compared for their emulsification efficiencies using different oily phases. It has been reported that well formulated SNEDDS is dispersed within seconds under gentle stirring conditions. Transmittance values of different mixtures are demonstrated in Table I. Results inferred that the oily phase Labrafil M 2125 CS and Maisine 35-1 in 1:1 ratio exhibited the highest emulsification efficiency with labrasol and Cremophor EL. Being non-ionic in nature, it has been considered that it is less toxic than ionic surfactants and are usually accepted for oral ingestion (Pouton, Porter, 2008). This encompasses effects on tight junction such as Labrasol (Hu et al., 2001), and inhibitory effects on p-glycoprotein (P-gp) and cytochrome P450 enzymes such as Cremophor EL (Chen, 2008; Rahman et al., 2013).

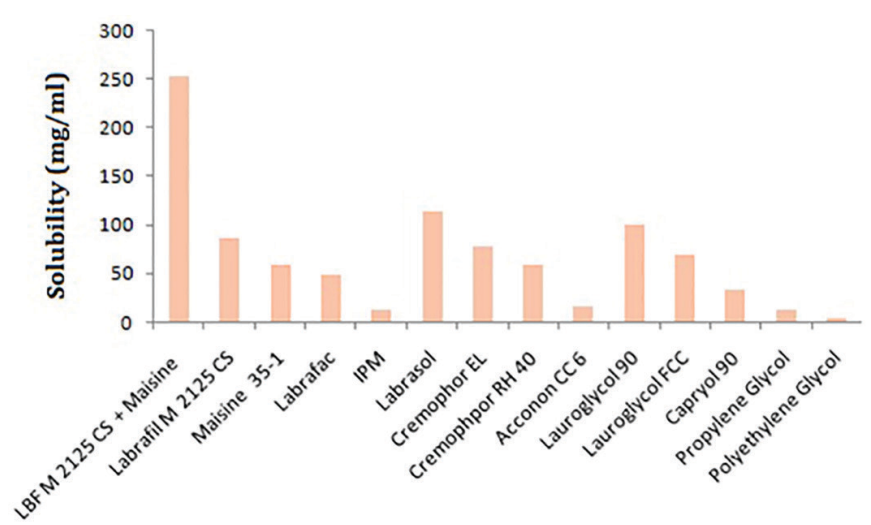

FIGURE 2 - Solubility of sertraline in various oils, surfactants and cosurfactants.

Addition of a cosurfactant to the surfactantcontaining formulation was reported to improve dispersibility and drug absorption from the formulation (Lawrence, Rees, 2000). In view of current investigation, five cosurfactants, namely Lauroglycol 90, Lauroglycol

TABLE I - Emulsification efficiency of various surfactants using different oily phases

\begin{tabular}{lcccc}
\hline \multirow{2}{*}{ Surfactant } & \multicolumn{4}{c}{ \% transmittance } \\
\cline { 2 - 5 } & Labrafil M 2125 CS & Maisine 35-1 & $\begin{array}{c}\text { LBF M 2125 CS + } \\
\text { Maisine (1:1) }\end{array}$ & Labrafac \\
\hline Labrasol & 91.2 & 72 & 97.8 & 9 \\
Cremophor EL & 39.8 & 47.4 & 87 & 54 \\
Cremophor RH40 & 59 & 79.3 & 83 & 42.6 \\
Acconon CC-6 & 8 & 21 & 42 & 14.3 \\
\hline
\end{tabular}


FCC, Caproyl 90, Propylene glycol and polyethylene glycol were compared. As depicted in Table II, the ratio of Labrafil M 2125 CS and Maisine 35-1 (1:1) exhibited good emulsification with cosurfactant Lauroglycol 90 showing maximum transmittance of $97.4 \%$ and $95.4 \%$ with Labrasol and Cremophor EL, respectively. Herein, solubility of the drug in different cosurfactants may judge the final selection. Results of solubility study demonstrated highest solubility in Lauroglycol 90.

TABLE II - Emulsification efficiency of various cosurfactants using surfactant labrasol and Cremophor EL and oily phases (LBF M 2125 CS + Maisine 35-1 (1:1)

\begin{tabular}{lcc}
\hline \multirow{2}{*}{ Co-surfactants } & \multicolumn{2}{c}{ \% Transmittance } \\
\cline { 2 - 3 } & Labrasol & Cremophor EL \\
\hline Lauroglycol 90 & 97.4 .4 & 95.4 \\
Lauroglycol FCC & 56.3 & 64 \\
Caproyl 90 & 45.9 & 44.3 \\
Propylene glycol & 32.5 & 45.5 \\
Polyethylene glycol & 34.6 & 36.4 \\
\hline
\end{tabular}

\section{Construction of ternary phase diagram}

Constructing phase diagrams is time consuming, particularly when the aim is to accurately delineate a phase boundary. Care was taken to ensure that observations are not made on metastable systems, although the free energy required to form an emulsion is very low, the formation is thermodynamically spontaneous (Craig et al., 1995). The relationship between the phase behaviour of a mixture and its composition can be captured with the aid of a phase diagram (Lawrence, Rees, 2000). LBF M 2125 CS and Maisine 35-1(1:1) as oil, Labrasol and Cremophor EL as surfactants and Lauroglycol 90 as cosurfactant, were put in separate Groups I and II to study the phase diagrams in detail.

\section{Group I}

In Group I, it can be observed that when surfactant was used alone without cosurfactant, [ $\mathrm{S}_{\text {mix }}$ ratio-1:0] (Figure 3A), very low amount of oil $(13 \% \mathrm{v} / \mathrm{v})$ could be solubilized at a high concentration $(53 \% \mathrm{v} / \mathrm{v})$ of surfactant. As the concentration of surfactant increased, solubilization of oil decreased. When surfactant and cosurfactant concentration was used in equal proportion $\left[\mathrm{S}_{\text {mix }}\right.$ ratio-1:1] (Figure 3B), it was observed that the nanoemulsion area decreased as compared to [ $\mathrm{S}_{\text {mix }}$ ratio-2:1] (Figure 3C), in which the nanoemulsion region in the phase diagram was found to be more and the oil solubilized upto $25 \% \mathrm{v} / \mathrm{v}$ with the $\mathrm{S}_{\text {mix }}$ concentration of $48 \% \mathrm{v} / \mathrm{v}$. When surfactant concentration was further increased to $\left[\mathrm{S}_{\text {mix }}\right.$ ratio-3:1] (Figure 3D), it was seen that nanoemulsion area decreased as compared to $\left[\mathrm{S}_{\text {mix }}\right.$ ratio- $\left.2: 1\right]$ and only upto $15 \% \mathrm{v} / \mathrm{v}$ oil could be solubilized with a surfactant concentration of $50 \% \mathrm{v} / \mathrm{v}$. When the cosurfactant concentration was further increased to $\left[\mathrm{S}_{\text {mix }}\right.$ ratio-1:2] (Figure 3E), the maximum amount of oil that could be solubilized was $14 \% \mathrm{v} / \mathrm{v}$ and that too at a higher concentration of $\mathrm{S}_{\text {mix }}(52 \% \mathrm{v} / \mathrm{v})$. Further, cosurfactant concentration was increased to make $\left[\mathrm{S}_{\text {mix }}\right.$ ratio-1:3] in which very small area of nanoemulsion was obtained which was unstable and showed phase separation after 12 hours (data not shown). It can be observed that the formulations prepared from phase diagrams in which the nanoemulsion area was extended towards aqueous rich apex could be diluted to a larger extent.

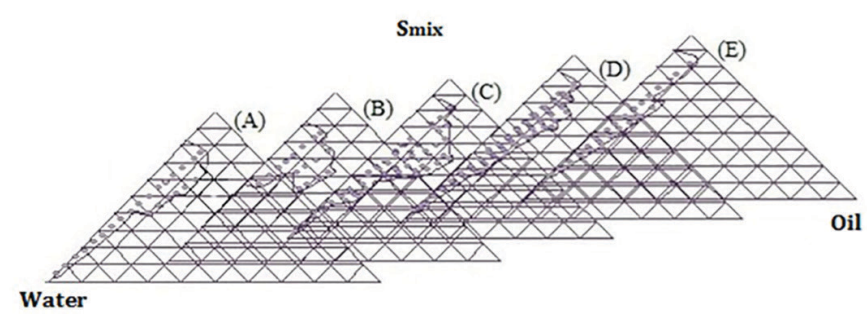

FIGURE 3 - Pseudo-ternary phase diagrams of Group I $\left[\mathrm{S}_{\text {mix }}\right.$ ratio $=1: 0(\mathrm{~A}), 1: 1(\mathrm{~B}), 2: 1$ (C), 3:1 (D), 1:2 (E)].

\section{Group II}

In case of Group II, the o/w nanoemulsion area was limited when surfactant was used alone $\left[\mathrm{S}_{\mathrm{mix}}\right.$ ratio-1:0] (Figure 4A). When cosurfactant was added along with surfactant in equal ratio $\left[\mathrm{S}_{\text {mix }}\right.$ ratio-1:1] (Figure 4B). There was slight improvement in nanoemulsion area, but it was not significant. It was observed in the phase diagram that $5 \%$ oil could be solubilized by $24 \%$ of $\mathrm{S}_{\text {mix }}$ and 10 to $30 \%$ oil could be solubilized by just increasing $\mathrm{S}_{\text {mix }}$ from 28 to $32 \% \mathrm{v} / \mathrm{v}$. When cosurfactant concentration was doubled, $\mathrm{S}_{\text {mix }}$ ratio 1:2 (Figure not shown), the total area of nanoemulsion decreased as compared to $1: 1$. In contrast, when surfactant concentration was increased as compared to cosurfactant, [ $\mathrm{S}_{\text {mix }}$ ratio 2:1] (Figure 4C), nanoemulsion region increased as compared to 1:1, giving an upward bulge in 10-20\% oil concentration where the minimum $\mathrm{S}_{\text {mix }}$ concentration required raised to $37 \%$. Nevertheless, the maximum concentration of oil that could be solubilized by this ratio was $30 \%$ utilizing just $35 \% \mathrm{v} / \mathrm{v}$ of $\mathrm{S}_{\text {mix }}$. When further surfactant concentration was increased to [ $\mathrm{S}_{\text {mix }}$ ratio-3:1] (Figure 4D), area of nanoemulsion decreased further and nanoemulsion gel 
area started coming in the phase diagram, which may be due to increased concentration of surfactant, although the maximum oil that could be solubilized by this ratio of $\mathrm{S}_{\text {mix }}$ was $33 \%$ with just $36 \% \mathrm{v} / \mathrm{v}$ of $\mathrm{S}_{\text {mix. }}$

It was noticed that it took a little more time for achieving equilibrium to form nanoemulsion, which is obvious because of high concentration of oil solubilized by less concentration of $\mathrm{S}_{\text {mix }}$. Further increasing the $\mathrm{S}_{\text {mix }}$ ratio to [ $\mathrm{S}_{\text {mix }}$ ratio-4:1] (Figure 4E), decreased nanoemulsion area but not to a large extend than $3: 1$, nanoemulsion area slowly decreased with increase in nanoemulsion gel area. The maximum concentration of oil that could be solubilized in $4: 1 \mathrm{~S}_{\text {mix }}$ ratio was $28 \% \mathrm{v} / \mathrm{v}$ with $37 \% \mathrm{v} / \mathrm{v}$ of $\mathrm{S}_{\text {mix }}$.

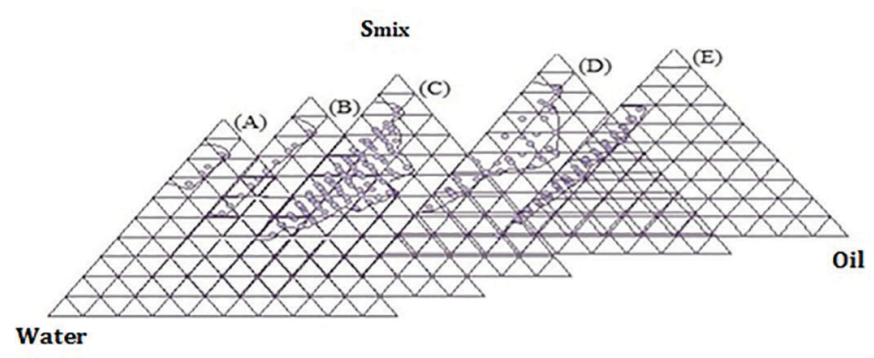

FIGURE 4 - Pseudo-ternary phase diagrams of Group II [ $\mathrm{S}_{\text {mix }}$ ratio $=1: 0(\mathrm{~A}), 1: 1(\mathrm{~B}), 2: 1(\mathrm{C}), 3: 1(\mathrm{D}), 4: 1(\mathrm{E})]$.

\section{Thermodynamic stability studies}

SNEDDS system undergoes in situ solubilization to form nanoemulsion system, and it should have stability such that it does not undergo precipitation, creaming or cracking. It is the thermostability which differentiates nanoemulsion from emulsions that have kinetic stability and will eventually phase separate (Shinoda et al., 1991). Therefore to check the stability, formulation was exposed to centrifugation, heating-cooling and freeze-thaw cycle. The formulations that passed these tests were selected for the dispersibility study in order to estimate the efficiency of dispersibility. Formulations selected from each phase diagram with their thermodynamic stability and dispersibility test are given in Table III and IV.

\section{Dispersibility test}

It is important that formed nanoemulsion in GIT should not undergo precipitation following phase separation with infinite dilution by GI fluids. It is observed more prominently with drugs having poor aqueous solubility or nanoemulsion which undergoes phase transition. To avoid such a situation, dispersibility studies in distilled water, in $0.1 \mathrm{~N} \mathrm{HCl}$ and 6.8 phosphate buffers was vital. Formulations passing the dispersibility test in all the three media in grade A and B were considered to pass the dispersibility test. Since, these formulations were certain to form nanoemulsion upon dilution in the aqueous environment; these were selected for further study. Formulations selected after thermodynamic stability and dispersibility test are given in Table III and IV.

\section{Interim stability study}

In many cases, prolonged storage might cause the drug to precipitate from the nanoemulsion; seed crystals start to appear and might grow to large crystalline materials that will precipitate out at the bottom of the vessel (Parmar et al., 2011). Therefore, to check the stability, formulations were subjected to interim stability study.

\section{Cloud point measurement}

The cloud point is the temperature above, which the formulation clarity turns into cloudiness and is an essential factor in the formulation consisting of non-ionic surfactants. It is responsible for the successful formation of a stable nanoemulsion (Itoh et al., 2002). When the temperature is higher than the cloud point, an irreversible phase separation will occur and the cloudiness of the preparation would have a bad effect on drug absorption, because of the dehydration of the polyethylene oxide moiety (Yosra, Magda, Ossama, 2009).

The cloud point value is affected by factors such as drug hydrophobicity, kind, combination, mixing ratio and amount of each of the oils, surfactants and cosurfactants used (Zhang et al., 2008). Since, both drug solubilization and formulation stability will decline with this phase separation, the cloud point of the formulation should be over $37^{\circ} \mathrm{C}$, which will avoid phase separation occurring in the GIT. Results (Table V) contented the stability of all formulations at physiological temperature in vivo.

\section{Percentage transmittance}

SNEDDS form nanoemulsion in GIT, it meets with patient acceptability but isotropic nature of formulations or percentage transmittance closer to $100 \%$ gives an indication of globule size in nanometer range. Also, with increase in $\%$ transmittance closer to $100 \%$ lead to decrease in globule size of nanoemulsion formed as observed in case of LF3 (Table V). The droplet size of the emulsion is a crucial factor in self-emulsification performance, because it determines the rate and extent of drug release as well as absorption (Shah et al., 1994). Thus, the formulation 
TABLE III - Thermodynamic and dispersibility test of formulations selected from Group I at a difference of 5\% v/v of oil

\begin{tabular}{|c|c|c|c|c|c|c|c|c|c|c|}
\hline \multirow{2}{*}{$\begin{array}{l}S_{\operatorname{mix}} \text { Ratio } \\
\text { (S:CoS) }\end{array}$} & \multicolumn{3}{|c|}{$\begin{array}{c}\% v / v \text { of different } \\
\text { components }\end{array}$} & \multicolumn{3}{|c|}{$\begin{array}{c}\text { Observations based on } \\
\text { thermodynamic stability test }\end{array}$} & \multicolumn{3}{|c|}{$\begin{array}{c}\text { Observations based on } \\
\text { dispersebility test }\end{array}$} & \multirow[t]{2}{*}{ Inference } \\
\hline & Oil & $\mathbf{S}_{\text {mix }}$ & Water & $\mathbf{H} / \mathbf{C}$ & Cent & Freez & Water & $\mathrm{HCl}$ & PB & \\
\hline \multirow{2}{*}{$\begin{array}{c}1: 0 \\
\text { (Fig. 3A) }\end{array}$} & 10 & 48 & 42 & $\sqrt{ }$ & $\mathrm{X}$ & - & - & - & - & Fail \\
\hline & 10 & 52 & 38 & $X$ & - & - & - & - & - & Fail \\
\hline \multirow{10}{*}{$\begin{array}{c}1: 1 \\
\text { (Fig. 3B) }\end{array}$} & 10 & 48 & 42 & $\mathrm{X}$ & - & - & - & - & - & Fail \\
\hline & 10 & 52 & 38 & $\sqrt{ }$ & $\sqrt{ }$ & $\sqrt{ }$ & A & $\mathrm{C}$ & - & Fail \\
\hline & 10 & 55 & 35 & $\mathrm{X}$ & - & - & - & - & - & Fail \\
\hline & 15 & 44 & 41 & $\sqrt{ }$ & $\mathrm{X}$ & - & - & - & - & Fail \\
\hline & 15 & 50 & 35 & $\sqrt{ }$ & $\sqrt{ }$ & $\sqrt{ }$ & A & A & A & Pass* \\
\hline & 15 & 55 & 30 & $\sqrt{ }$ & $\sqrt{ }$ & $\sqrt{ }$ & B & B & B & Pass \\
\hline & 20 & 41 & 39 & $\mathrm{X}$ & - & - & - & - & - & Fail \\
\hline & 20 & 46 & 34 & $\sqrt{ }$ & $\sqrt{ }$ & $\sqrt{ }$ & A & A & A & Pass* \\
\hline & 20 & 52 & 28 & $\sqrt{ }$ & $\sqrt{ }$ & $\sqrt{ }$ & A & $\mathrm{B} / \mathrm{C}$ & $\mathrm{C}$ & Fail \\
\hline & 25 & 48 & 27 & $\sqrt{ }$ & $\mathrm{X}$ & - & - & - & - & Fail \\
\hline \multirow{10}{*}{$\begin{array}{c}2: 1 \\
\text { (Fig. 3C) }\end{array}$} & 10 & 40 & 50 & $\mathrm{X}$ & - & - & - & - & - & Fail \\
\hline & 10 & 50 & 40 & $\sqrt{ }$ & $\sqrt{ }$ & $\sqrt{ }$ & A & A & A & Pass \\
\hline & 10 & 52 & 38 & $\sqrt{ }$ & $\sqrt{ }$ & $\sqrt{ }$ & A & A & B & Pass \\
\hline & 15 & 44 & 41 & $\sqrt{ }$ & $\mathrm{X}$ & - & - & - & - & Fail \\
\hline & 15 & 46 & 39 & $\sqrt{ }$ & $\sqrt{ }$ & $\sqrt{ }$ & A & A & A & Pass* \\
\hline & 15 & 50 & 35 & $\sqrt{ }$ & $\sqrt{ }$ & $\sqrt{ }$ & A & $\mathrm{A} / \mathrm{B}$ & A & Pass \\
\hline & 20 & 52 & 28 & $\sqrt{ }$ & $\sqrt{ }$ & $\sqrt{ }$ & A & $\mathrm{A} / \mathrm{B}$ & A & Pass* \\
\hline & 20 & 54 & 26 & $\sqrt{ }$ & $\sqrt{ }$ & $\sqrt{ }$ & A & $\mathrm{A} / \mathrm{B}$ & B & Pass \\
\hline & 20 & 56 & 24 & $\sqrt{ }$ & $\sqrt{ }$ & $\sqrt{ }$ & B & $\mathrm{C}$ & - & Fail \\
\hline & 25 & 48 & 27 & $\sqrt{ }$ & $\sqrt{ }$ & $\sqrt{ }$ & A & A & A & Pass* \\
\hline \multirow{4}{*}{$\begin{array}{c}3: 1 \\
\text { (Fig. 3D) }\end{array}$} & 10 & 40 & 50 & $\sqrt{ }$ & $\mathrm{X}$ & - & - & - & - & Fail \\
\hline & 10 & 44 & 46 & $\sqrt{ }$ & $\sqrt{ }$ & $\sqrt{ }$ & A & B & $\mathrm{C}$ & Fail \\
\hline & 10 & 48 & 42 & $\sqrt{ }$ & $\sqrt{ }$ & $\sqrt{ }$ & B & $\mathrm{C}$ & - & Fail \\
\hline & 15 & 50 & 35 & $\sqrt{ }$ & $\sqrt{ }$ & $\mathrm{X}$ & - & - & - & Fail \\
\hline \multirow{2}{*}{$\begin{array}{c}1: 2 \\
\text { (Fig. 3E) }\end{array}$} & 10 & 45 & 45 & $\sqrt{ }$ & $\sqrt{ }$ & $\sqrt{ }$ & $\mathrm{D}$ & - & - & Fail \\
\hline & 10 & 52 & 38 & $\sqrt{ }$ & $\mathrm{X}$ & - & - & - & - & Fail \\
\hline
\end{tabular}

H/C- Heating cooling cycle; Cent- Centrifugation; Freez- Freeze thaw cycle; *Formulation selected

has the capacity to undergo enhanced absorption and thus ability to have increased oral bioavailability.

\section{Viscosity determination}

Viscosity studies are necessary for SNEDDS to characterize the system physically and to control its stability. The viscosity of all the formulations were determined (Table V). It was observed that the viscosity of LF3 was minimum, which may be due to the less oil content.

\section{Droplet size and polydispersity index}

The droplet size of the nanoemulsion is important factor in SNEDDS formulation, as this determines the rate and extent of drug release as well as absorption. The PDI reflects the uniformity of particle diameter and can be used to depict the size distribution of nanoemulsion population. The smaller the droplet size, the larger the interfacial surface area will be provided for drug absorption (Gershanik, Benita, 2000; Kang et al., 2004). Moreover some authors have paid much attention to the 
TABLE IV - Thermodynamic dispersibility test of formulations selected from Group II at a difference of 5\% v/v of oil

\begin{tabular}{|c|c|c|c|c|c|c|c|c|c|c|}
\hline \multirow{2}{*}{$\begin{array}{c}S_{\text {mix }} \text { Ratio } \\
(\mathrm{S}: \mathrm{CoS})\end{array}$} & \multicolumn{3}{|c|}{$\% \mathrm{v} / \mathrm{v}$ of different components } & \multicolumn{3}{|c|}{$\begin{array}{c}\text { Observations based on } \\
\text { thermodynamic stability test }\end{array}$} & \multicolumn{3}{|c|}{$\begin{array}{c}\begin{array}{c}\text { Observations based on } \\
\text { dispersebility test }\end{array} \\
\end{array}$} & \multirow[t]{2}{*}{ Inference } \\
\hline & Oil & $\mathbf{S}_{\text {mix }}$ & Water & $\mathbf{H} / \mathbf{C}$ & Cent & Freez & Water & $\mathrm{HCl}$ & PB & \\
\hline \multirow{14}{*}{$\begin{array}{c}2: 1 \\
\text { (Fig. 4C) }\end{array}$} & 10 & 35 & 55 & $\mathrm{X}$ & - & - & - & - & - & Fail \\
\hline & 10 & 42 & 48 & $\sqrt{ }$ & $\sqrt{ }$ & $\sqrt{ }$ & A & $\mathrm{C}$ & A & Fail \\
\hline & 10 & 48 & 42 & $\sqrt{ }$ & $\sqrt{ }$ & $\sqrt{ }$ & $\mathrm{C}$ & - & - & Fail \\
\hline & 15 & 44 & 46 & $\sqrt{ }$ & $\mathrm{X}$ & - & - & - & - & Fail \\
\hline & 15 & 45 & 40 & $\sqrt{ }$ & $\sqrt{ }$ & $\sqrt{ }$ & $\mathrm{A}$ & $\mathrm{A}$ & A & Pass* \\
\hline & 15 & 50 & 35 & $\sqrt{ }$ & $\sqrt{ }$ & $\sqrt{ }$ & $\mathrm{A}$ & $\mathrm{A}$ & $\mathrm{A} / \mathrm{B}$ & Pass \\
\hline & 20 & 42 & 38 & $\sqrt{ }$ & $\sqrt{ }$ & $\sqrt{ }$ & A & A & A & Pass* \\
\hline & 20 & 45 & 35 & $\sqrt{ }$ & $\sqrt{ }$ & $\sqrt{ }$ & A & A & A & Pass \\
\hline & 20 & 48 & 32 & $\sqrt{ }$ & $\sqrt{ }$ & $\sqrt{ }$ & A & A & $\mathrm{A} / \mathrm{B}$ & Pass \\
\hline & 25 & 28 & 47 & $\sqrt{ }$ & $\sqrt{ }$ & $\sqrt{ }$ & A & A & A & Pass* \\
\hline & 25 & 32 & 43 & $\sqrt{ }$ & $\sqrt{ }$ & $\sqrt{ }$ & A & A & B & Pass \\
\hline & 25 & 47 & 28 & $\sqrt{ }$ & $\sqrt{ }$ & $\sqrt{ }$ & $\mathrm{C}$ & - & - & Fail \\
\hline & 30 & 30 & 40 & $\mathrm{X}$ & - & - & - & - & - & Fail \\
\hline & 30 & 35 & 35 & $\sqrt{ }$ & $\sqrt{ }$ & $\sqrt{ }$ & $\mathrm{D}$ & - & - & Fail \\
\hline \multirow{15}{*}{$\begin{array}{c}3: 1 \\
\text { (Fig. 4D) }\end{array}$} & 10 & 40 & 50 & $X$ & - & - & - & - & - & Fail \\
\hline & 10 & 48 & 42 & $\sqrt{ }$ & $\sqrt{ }$ & $\sqrt{ }$ & $\mathrm{C}$ & - & - & Fail \\
\hline & 10 & 54 & 36 & $\sqrt{ }$ & $\sqrt{ }$ & $\sqrt{ }$ & B & B & $\mathrm{C}$ & Fail \\
\hline & 15 & 44 & 41 & $\sqrt{ }$ & $\sqrt{ }$ & $\sqrt{ }$ & A & A & A & Pass* \\
\hline & 15 & 45 & 40 & $\sqrt{ }$ & $\sqrt{ }$ & $\sqrt{ }$ & A & A & A & Pass \\
\hline & 15 & 52 & 33 & $\sqrt{ }$ & $\mathrm{X}$ & - & - & - & - & Fail \\
\hline & 20 & 32 & 48 & $\mathrm{X}$ & - & - & - & - & - & Fail \\
\hline & 20 & 40 & 40 & $\sqrt{ }$ & $\sqrt{ }$ & $\sqrt{ }$ & A & A & A & Pass* \\
\hline & 20 & 52 & 28 & $\sqrt{ }$ & $\sqrt{ }$ & $\sqrt{ }$ & A & A & A & Pass \\
\hline & 25 & 32 & 43 & $\sqrt{ }$ & $X$ & - & - & - & - & Fail \\
\hline & 25 & 35 & 40 & $\sqrt{ }$ & $\sqrt{ }$ & $\sqrt{ }$ & B & $\mathrm{C}$ & - & Fail \\
\hline & 25 & 42 & 33 & $\sqrt{ }$ & $\sqrt{ }$ & $\sqrt{ }$ & A & $\mathrm{A}$ & A & Pass* \\
\hline & 30 & 28 & 42 & $\sqrt{ }$ & $\sqrt{ }$ & $X$ & - & - & - & Fail \\
\hline & 30 & 30 & 40 & $\sqrt{ }$ & $\sqrt{ }$ & $\sqrt{ }$ & $\mathrm{D}$ & - & - & Fail \\
\hline & 30 & 36 & 34 & $\mathrm{X}$ & - & - & - & - & - & Fail \\
\hline \multirow{11}{*}{$\begin{array}{c}4: 1 \\
\text { (Fig. 4E) }\end{array}$} & 10 & 40 & 50 & $X$ & - & - & - & - & - & Fail \\
\hline & 10 & 48 & 42 & $\sqrt{ }$ & $\sqrt{ }$ & $\sqrt{ }$ & B & $\mathrm{C}$ & - & Fail \\
\hline & 10 & 54 & 36 & $\sqrt{ }$ & $\sqrt{ }$ & $\sqrt{ }$ & $\mathrm{D}$ & - & - & Fail \\
\hline & 15 & 40 & 45 & $X$ & - & - & - & - & - & Fail \\
\hline & 15 & 48 & 37 & $\sqrt{ }$ & $\sqrt{ }$ & $\sqrt{ }$ & $\mathrm{C}$ & - & - & Fail \\
\hline & 15 & 52 & 33 & $\sqrt{ }$ & $\sqrt{ }$ & $\sqrt{ }$ & & & & Pass \\
\hline & 20 & 30 & 50 & $X$ & - & - & - & - & - & Fail \\
\hline & 20 & 33 & 47 & $\sqrt{ }$ & $\sqrt{ }$ & $X$ & - & - & - & Fail \\
\hline & 20 & 48 & 32 & $\sqrt{ }$ & $\sqrt{ }$ & $\sqrt{ }$ & B & A & $\mathrm{D}$ & Fail \\
\hline & 25 & 32 & 43 & $\sqrt{ }$ & $\sqrt{ }$ & $\sqrt{ }$ & $\mathrm{D}$ & - & - & Fail \\
\hline & 25 & 35 & 40 & $X$ & - & - & - & - & - & Fail \\
\hline
\end{tabular}


TABLE V - Droplet size, polydispersity index, viscosity, percentage transmittance and cloud point of liquid SNEDDS

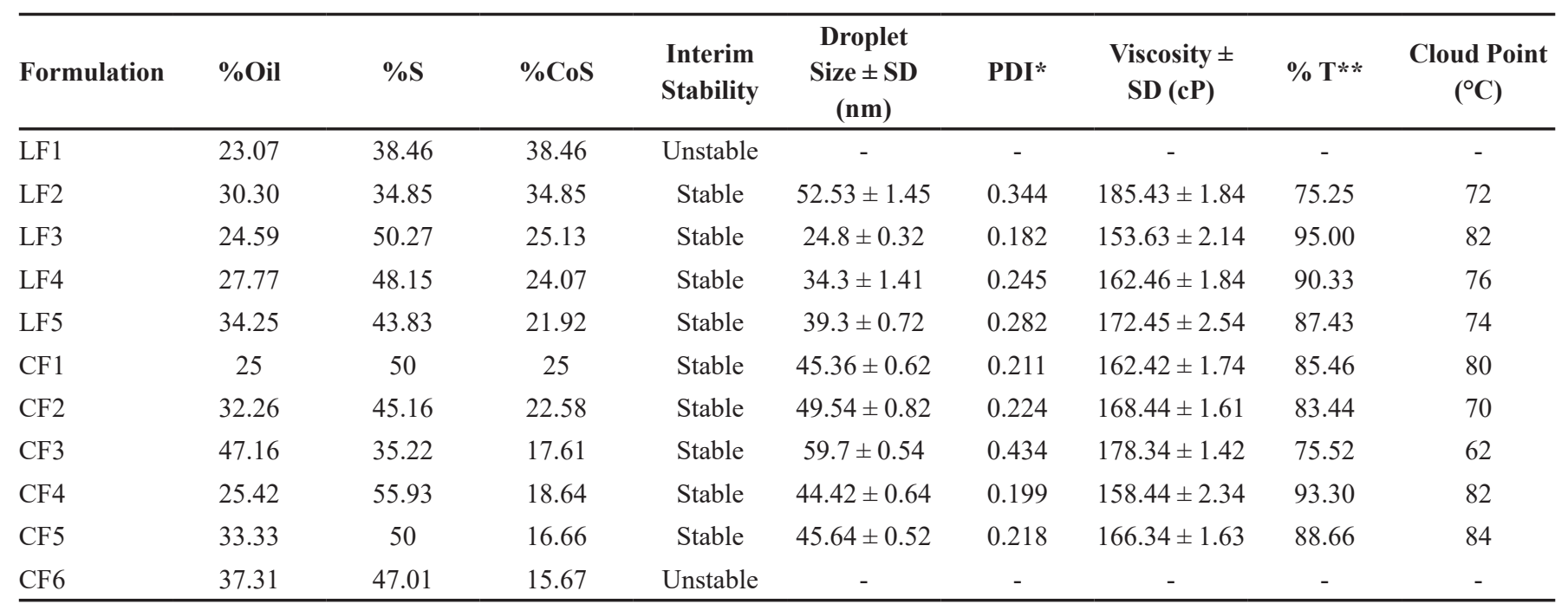

*polydispersity index, **percentage transmittance

drug solubilization capacity in the lipid formulations when dilution and digestion in the GIT, which would influence the subsequent dispersion and absorption of drug (Gao et al., 2003; Kossena et al., 2004; Porter et al., 2004).

The droplet size distribution of all the formulations is given in Table $\mathrm{V}$. The formulations were in nanometer size range $(24.8 \mathrm{~nm}-59.7 \mathrm{~nm})$. A decrease in the content of the oil phase resulted in a proportional decrease in particle size, because of the simultaneous increase in the $\mathrm{S}_{\text {mix }}$ proportion. The droplet size and polydispersity index were minimum in the case of LF3 (Figure 5) suggesting uniformity in the droplet size.

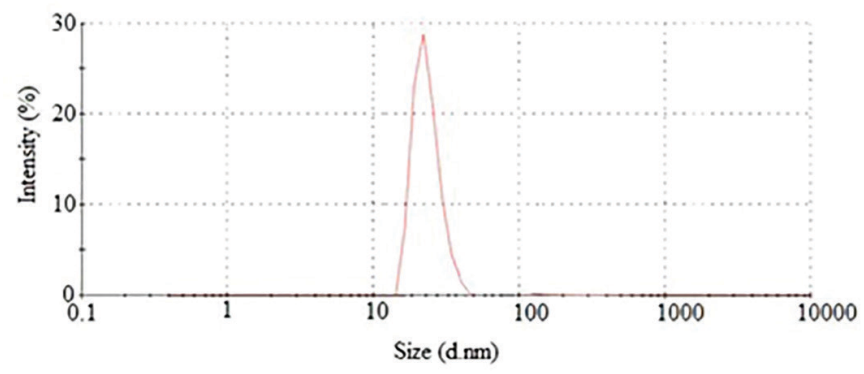

FIGURE 5 - Particle size distribution of LF3 formulation at 24 $\mathrm{h}$ post dilution with distilled water using Malvern Zetasizer.

\section{In vitro release study}

Three formulations were selected from each group having smallest droplet size, least viscosity and polydispersity, higher percentage transmittance and cloud point. The studies were performed to evaluate the sertraline release characteristics from developed
SNEDDS. The highest release of sertraline (97\%) was observed in case of LF3 (Figure 6). This was because of small globule size, and eventually higher surface area in case of nanoemulsions, which permit faster rate of drug release. Thus, this greater availability of dissolved sertraline from the SNEDDS formulation could lead to higher absorption and oral bioavailability.

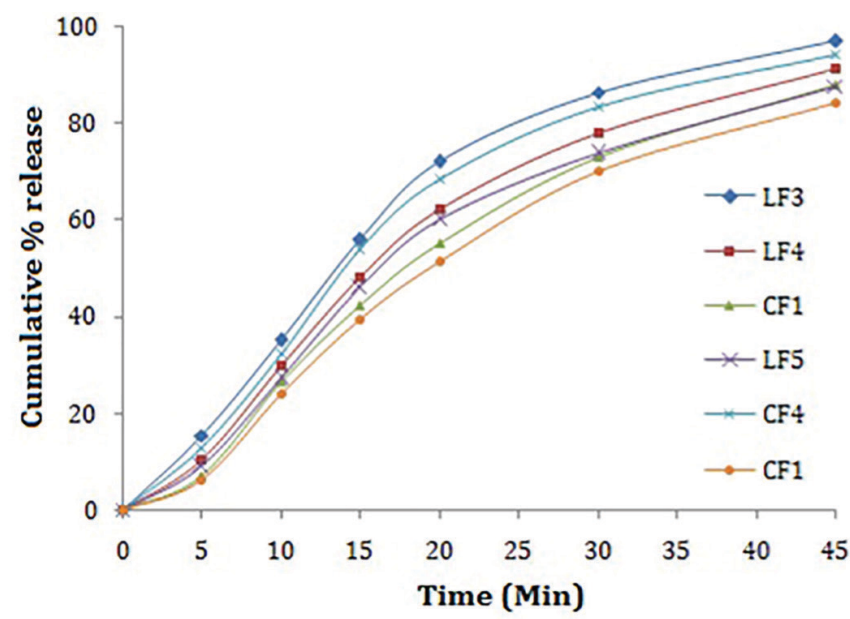

FIGURE 6 - Dissolution profile of optimized liquid SNEDDS. Data are expressed as mean $(n=3)$.

\section{Optimization of solid SNEDDS}

It was observed that solid adsorbents such as dibasic calcium phosphate, anhydrous lactose, calcium carbonate, magnesium carbonate did not have good adsorption capacity. Aerosil 200 exhibited good adsorption (1:2 ratio), excellent flow properties and optimum bulk density to 
be compressed into tablets. Briefly, solid SNEDDS was prepared containing a fixed proportion of sertraline $25 \mathrm{mg}$ (single dose) dissolved in a mixture of oily liquid $(59.58 \%$ $\mathrm{w} / \mathrm{w})$, mixed with Aerosil (34.42\% w/w), sodium starch glycolate $(5 \% \mathrm{w} / \mathrm{w})$ and magnesium stearate $(1 \% \mathrm{w} / \mathrm{w})$. Angle of repose of solid SNEDDS was $24.85 \pm 0.02$, Carr's index was found to be $11.14 \pm 0.43 \%$, Hausner's ratio was $1.13 \pm 0.01$ which indicated good flow properties of solid SNEDDS.

\section{Reconstituting properties and physical characterization}

The solid SNEDDS preserved the self-emulsification performance of the liquid SNEDDS and on reconstitution in distilled water yielded nanoemulsion with globule size of $30.7 \mathrm{~nm}$, which was similar with the droplet size of liquid SNEDDS $(24.8 \mathrm{~nm})$ with a polydispersity index of 0.163 . The globule size of the nanoemulsion slightly increased after adsorption of liquid formulation over Aerosil, but the difference was not statistically significant $(p>0.05)$.

The physical state of sertraline in the solid SNEDDS was verified by X-ray powder diffractograms (Figure 7), since it would have an important influence on the in vitro and in vivo release characteristics. Due to the dilution by Aerosil, sodium starch glycolate and magnesium stearate a few peaks appeared in the physical mixture of sertraline and Aerosil, sodium starch glycolate, magnesium stearate (curve B). No obvious peaks representing crystals of sertraline were seen for the solid SNEDDS (curve C).

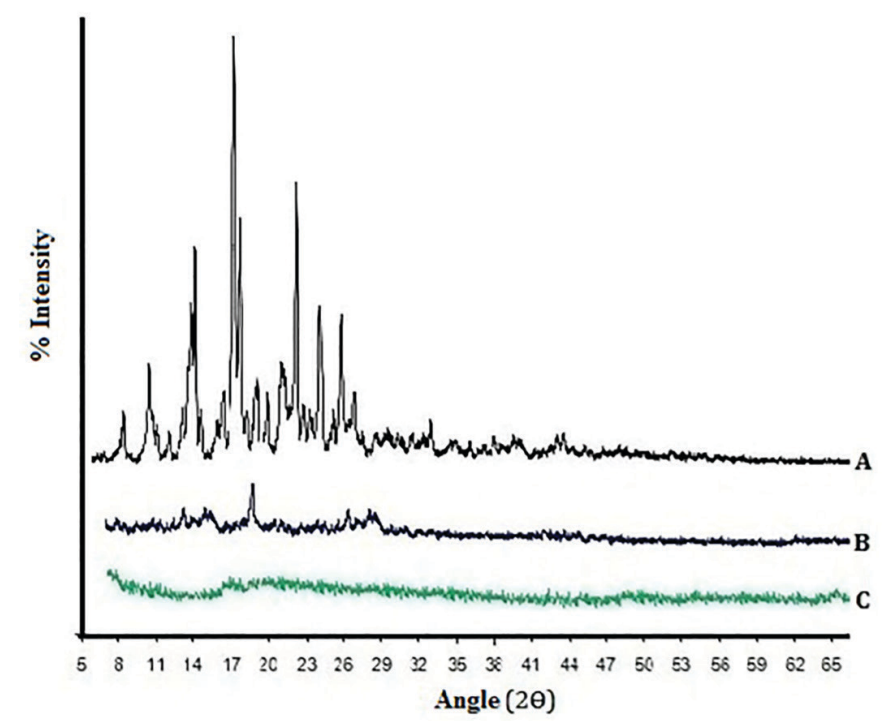

FIGURE 7 - X-ray powder diffractometry of(A) pure sertraline, (B) physical mixture, and (C) solid SNEDDS.

\section{In vitro comparative release study}

Release study was performed to compare the release of sertraline from optimized liquid and solid SNEDDS (tablet) with the release from plain sertraline. The release of sertraline from solid SNEDDS was $94.3 \%$, significantly higher $(\mathrm{p}<0.01)$ compared with the plain sertraline (Figure 8). However, the release rate and extent of liquid SNEDDS was slightly higher than that of the solid SNEDDS. Three reasons may probably explain the result. Firstly, there is a disintegration process for the tablets, which will delay the first step of drug release. Secondly, the excipients such as Aerosil will have a relatively strong interaction with the adsorbed SNEDDS. Third reason may be due to slight increase in droplet size after reconstitution which provides smaller surface area, probably impairing the release rate and extent of sertraline.

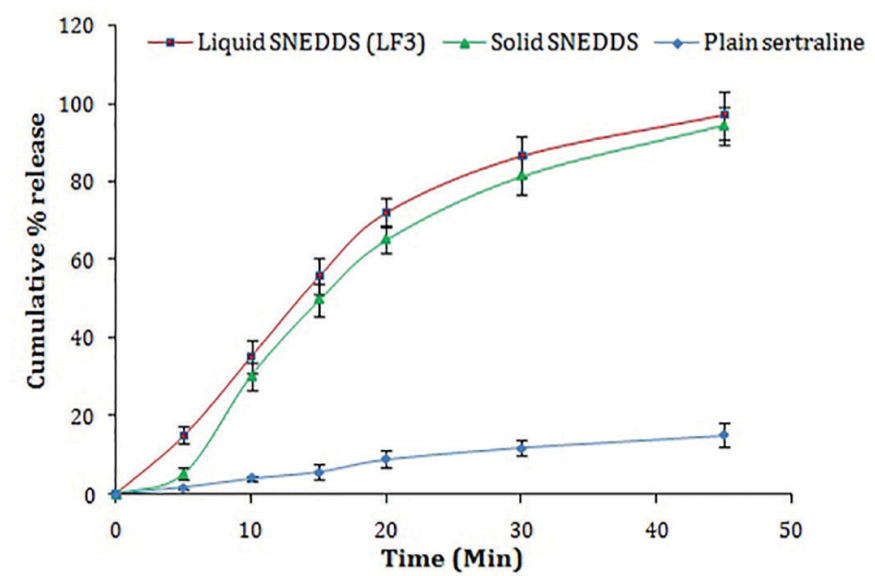

FIGURE 8 - Release patterns of sertraline loaded liquid (LF3) and solid SNEDDS compared to that from plain sertraline. Data are expressed as mean $(n=3)$.

\section{In vivo study}

The plasma concentrations vs. time profiles are shown in Figure 9, and the pharmacokinetic parameters are summarized in Table VI. Dosing the aqueous suspensions of sertraline resulted in the lowest average sertraline plasma concentrations. However, the $\mathrm{AUC}_{0-\mathrm{t}}$ was about 6-and 5-times greater when sertraline was administered as liquid and solid SNEDDS, compared with the $\mathrm{AUC}_{0-\mathrm{t}}$ obtained for the aqueous suspension of sertraline.

The liquid and solid SNEDDS gave mean values of $\mathrm{C}_{\max } 220.51 \mathrm{ng} / \mathrm{mL}$ and $209.62 \mathrm{ng} / \mathrm{mL}$, which were 17.75- and 16.87-fold higher than the $\mathrm{C}_{\max }$ obtained with the same dose of sertraline administered as an aqueous suspension $\left(12.42 \mathrm{ng} / \mathrm{mL}\right.$ ). The $\mathrm{T}_{\text {max }}$ of both the liquid (1.0 h) and solid SNEDDS (1.83 h) was significantly lower 


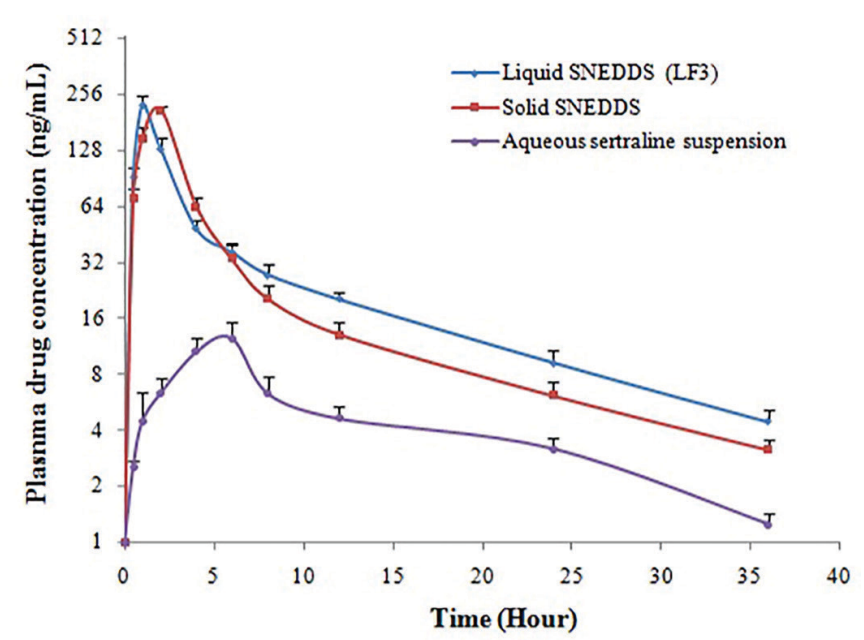

FIGURE 9 - Mean plasma concentration profile of sertraline after oral administration of liquid (LF3) and solid SNEDDS, aqueous suspension of plain sertraline. Data are expressed as mean $(n=3)$.

than $\mathrm{T}_{\max }$ obtained with aqueous suspension of sertraline $(5.92 \mathrm{~h})$. Also, the optimized formulations showed greater improvement in relative bioavailability compared to aqueous suspension of sertraline. These results reveal that formulations of sertraline as liquid and solid SNEDDS results in a significantly increased absorption, compared with that from the aqueous suspension of plain sertraline.

The improved absorption of sertraline was probably due to the enhanced solubilization. Sertraline dissolved in liquid and solid adsorb powder could be directly absorbed as the nanoemulsion droplets in the GIT, without a dissolution step. The small droplet size of less than $50 \mathrm{~nm}$ of oil-in-water nanoemulsions might penetrate the site of absorption via transcellular pathway.

The oil used in the formulations is probably to protect the drug from enzyme degradation (Gursoya, Benita 2004). Nonionic surfactants not only improved the solubility and dissolution of the drug may also reduce the interfacial surface tension and enhance penetration of the drug through the epithelial cells. In addition, Labrasol has been reported to increase tight junction permeability (Lindmark et al., 1995), leading to enhanced drug absorption by paracellular pathway. The pharmacokinetic data in male SD rats imply that SNEDDS in both liquid and solid formulation developed in this study could improve dissolution and absorption of sertraline.

\section{CONCLUSION}

The present study demonstrated that both the liquid and solid SNEDDS were successfully developed. The optimized formulation readily released the lipid phase to form a fine oil-in-water nanoemulsion, with a narrow size distribution. Tablets were able to carry SNEDDS and possess acceptable pharmacopeia requirements for tablets. In addition, they were able to introduce the SNEDDS into the dissolution media where it was efficiently transformed into nanoemulsion by the gentle agitation provided in the dissolution experiment. Modifying Aerosil physical from amorphous into granules improved the physical properties of both liquisolid powders and tablets. It enhanced the adsorption power and compressibility of liquisolid tablets. The oral absorption of sertraline from both the formulations was much greater than the plain sertraline. Successfully, SNET were able to introduce sertraline in a unique immediate-release dosage form with improved bioavailability.

\section{ACKNOWLEDGEMENTS}

One of the authors, Md. A. Rahman is highly grateful to university grant commission (UGC) to provide senior research fellowship (SRF). The author is also thankful to department of science and technology (DST), Gov. of India for providing travel grant to attend international conference "Colloids and Nanomedicine 2012" in Amsterdam organized by Elsevier.

TABLE VI - Relative bioavailability and pharmacokinetics parameters after oral administration of liquid (LF3) and solid SNEDDS, aqueous suspension of plain sertraline. All values reported are mean $\pm \operatorname{SD}(n=3)$

\begin{tabular}{lcccc}
\hline Formulations & $\begin{array}{c}\mathbf{T}_{\max }{ }^{\mathrm{a}} \\
\mathbf{( h )}\end{array}$ & $\begin{array}{c}\mathbf{C}_{\max }{ }^{\mathrm{b}} \\
(\mathbf{n g} / \mathbf{m L})\end{array}$ & $\begin{array}{c}\mathbf{A U C}_{\mathbf{0}_{\rightarrow} \mathrm{c}^{\mathrm{c}}} \\
(\mathbf{n g . h} / \mathbf{m L})\end{array}$ & $\begin{array}{c}\text { Relative } \\
\text { Bioavailability (\%) }\end{array}$ \\
\hline Liquid SNEDDS (LF3) & $1.0 \pm 0.26^{*}$ & $220.51 \pm 27.53^{* *}$ & $1072.89 \pm 283.5^{* *}$ & $589.08^{\dagger}$ \\
Solid SNEDDS & $1.83 \pm 0.35^{*}$ & $209.62 \pm 19.16^{* *}$ & $917.99 \pm 263.7^{* *}$ & $504.03^{\dagger}$ \\
Aq. suspension of sertraline & $5.92 \pm 0.47$ & $12.42 \pm 2.65$ & $182.13 \pm 32.65$ & - \\
\hline
\end{tabular}

${ }^{*} \mathrm{p}<0.01$ and $^{* *} \mathrm{p}<0.001$ when compared with aq. suspension of sertraline using one way ANOVA; ${ }^{\mathrm{a}}$ time of peak concentration; ${ }^{\mathrm{b}}$ peak of maximum concentration; ${ }^{\mathrm{c}}$ area under the concentration time profile curve until last observation; ${ }^{\dagger}$ relative bioavailability compared to aq. suspension of plain sertraline. 


\section{CONFLICT OF INTEREST}

There is no conflict of interest.

\section{REFERENCES}

Abbaspour M, Makhmalzadeh BS. Development and evaluation of a solid self-nanoemulsifying drug delivery system for loratadin by extrusion-spheronization. Adv Pharm Bull. 2014;4(2):113-119.

Chen ML. Lipid excipients and delivery systems for pharmaceutical development: a regulatory perspective. Adv Drug Deliv Rev. 2008;60(6):768-777.

Craig DQM, Barker SA, Banning D, Booth SW. An investigation into the mechanisms of self-emulsification using particle size analysis and low frequency dielectric spectroscopy. Int J Pharm. 1995;114(1):103-110.

Date AA, Nagarsenker MS. Design and evaluation of selfnanoemulsifying drug delivery systems (SNEDDS) for cefpodoxime proxetil. Int J Pharm. 2007;329(1-2):166-172.

Flament MF, Lane RM, Zhu R, Ying Z. Predictors of an acute antidepressant response to fluoxetine and sertraline. Int Clin Psychopharmacol. 1999;14(5):259-275.

Gao P, Rush BD, Pfund WP, Huang T, Bauer JM, Morozowich W, Kuo MS, Hageman MJ. Development of a supersaturable SEDDS (S-SEDDS) formulation of paclitaxel with improved oral bioavailability. J Pharm Sci. 2003;92(12):2386-98.

Gershanik T, Benita S. Self-dispersing lipid formulations for improving oral absorption of lipophilic drugs. Eur J Pharm Biopharm. 2000;50(1):179-188.

Gursoya RN, Benita S. Self-emulsifying drug delivery systems (SEDDS) for improved oral delivery of lipophilic drugs. Biomed Pharmacother. 2004;58(3):173-182.

Hu Z, Tawa R, Konishi T, Shibata N, Takada K. A novel emulsifier, Labrasol, enhances gastrointestinal absorption of gentamicin. Life Sci. 2001;69(24):2899-2910.

Humberstone AJ, Charman WN. Lipid-based vehicles for the oral delivery of poorly water-soluble drugs. Adv Drug Del Rev. 1997;25(1):103-128.
Itoh K, Tozuka Y, Oguchi T, Yamamoto K. Improvement of physicochemical properties of N-4472 part I formulation design by using self-microemulsifying system. Int J Pharm. 2002;238(1-2):153-160.

Kang BK, Lee JS, Chon SK, Jeong SY, Yuk SH, Khang G, Lee HB, Cho SH. Development of self-microemulsifying drug delivery systems (SMEDDS) for oral bioavailability enhancement of simvastatin in beagle dogs. Int J Pharm. 2004;274(1-2):65-73.

Kararli TT, Needham TE, Grifaen M, Schoenhard G, Ferro LJ, Alcorn L. Oral delivery of a rennin inhibitor compound using emulsion formulation. Pharm Res. 1992;9(7):888-893.

Khoo SM, Humberstone AJ, Porter CJH, Edwards GA, Charman WN. Formulation design and bioavailability assessment of lipidic self-emulsifying formulations of halofantrine. Int J Pharm. 1998;167(1-2):155-164.

Kossena GA, Charman WN, Boyd BJ, Dunstan DE, Porter CJH. Probing drug solubilization patterns in the gastrointestinal tract after administration of lipid-based delivery systems: a phase diagram approach. J Pharm Sci. 2004;93(2):332-48.

Lawrence MJ, Rees GD. Microemulsion-based media as novel drug delivery systems. Adv Drug Deliv Rev. 2000;45(1):89-121.

Lindmark T, Nikkila T, Artursson P. Mechanisms of absorption enhancement by medium chain fatty acids in intestinal epithelial Caco-2 monolayers. J Pharmacol Exp Ther. 1995;275(2):958-964.

Mou D, Chen H, Du D, Mao C, Wan J, Xu H. Hydrogelthickened nanoemulsion system for topical delivery of lipophilic drugs. Int J Pharm. 2008;353(1-2):270-276.

Nielsen FS, Petersen KB, llertz AM. Bioavailability of probucol from lipid and surfactant based formulations in minipigs: influence of droplet size and dietary state. Eur J Pharm Biopharm. 2008;69(2):553-562.

Parmar N, Singla N, Amin S, Kohli K. Study of cosurfactant effect on nanoemulsifying area and development of lercanidipine loaded self nanoemulsifying drug delivery system. Colloids Surf B Biointerfaces. 2011;86(2):327-338.

Porter CJH, Kaukonen AM, Taillardat-Bertschinger A, Boyd BJ, O'Connor JM, Edwards GA, Charman WN. Use of in vitro lipid digestion data to explain the in vivo performance of triglyceridebased oral lipid formulations of poorly water-soluble drugs: studies with halofantrine. J Pharm Sci. 2004;93(5):1110-21. 
Porter CJH, Pouton CW, Cuine JF, Charman WN. Enhancing intestinal drug solubilization using lipid-based delivery systems. Adv Drug Deliv Rev. 2008;60(6):673-691.

Pouton CW, Porter CJH. Formulation of lipid-based delivery systems for oral administration: materials, methods and strategies. Adv Drug Deliv Rev. 2008;60(6):625-637.

Pouton CW. Formulation of self-emulsifying drug delivery systems. Adv Drug Deliv Rev. 1997;25(1):47-58.

Rahman MA, Harwansh R, Mirza MA, Hussain S, Hussain A. Oral lipid based drug delivery system (LBDDS): Formulation, characterization and application: a review. Curr Drug Deliv. 2011;8(4):330-345.

Rahman MA, Hussain A, Hussain S, Harwansh R, Mirza MA, Iqbal Z. Role of excipients in successful development of selfemulsifying/microemulsifying drug delivery system (SEDDS/ SMEDDS). Drug Dev Ind Pharm. 2013;39(1):1-19.

Rao SVR, Shao J. Self-nanoemulsifying drug delivery systems (SNEDDS) for oral delivery of protein drugs: formulation development. Int J Pharm. 2008;362(1-2):2-9.

Rashid R, Kim DW, Yousaf AM, Mustapha O, Fakhar ud Din, Park JH, Yong CS, Oh Y, Youn YS, KJ Oh, Choi H. Comparative study on solid self-nanoemulsifying drug delivery and solid dispersion system for enhanced solubility and bioavailability of ezetimibe. Int J Nanomedicine. 2015;10:61476159.

Schwendener RA, Schott H. Lipophilic 1-beta-darabinofuranosyl cytosine derivatives in liposomal formulations for oral and parenteral antileukemic therapy in the murine L1210 leukemia model. J Cancer Res Clin Oncol. 1996;122(12):723726.
Serajuddin ATM. Solid dispersion of poorly water-soluble drugs: early promises, subsequent problems and recent breakthroughs. J Pharm Sci. 1999;88(10):1058-1066.

Shafiq S, Shakeel F, Talegaonkar S, Ahmad FJ, Khar RK, Ali M. Development and bioavailability assessment of ramipril nanoemulsion formulation. Eur J Pharm Biopharm. 2007a;66(2):227-243.

Shafiq S, Shakeel F, Talegaonkar S, Ali J, Baboota S, Ahuja A, Khar RK, Ali M. Formulation development and optimization using nanoemulsion technique: a technical note. AAPS Pharm Sci Tech. 2007b;8(2):E1-E6.

Shah NH, Carvagal MT, Patel Infeld MH, Malick AW. Self-emulsifying drug delivery systems (SEDDS) with polyglycolyzed glycerides for improving in vitro dissolution and oral absorption of lipophilic drugs. Int J Pharm. 1994;106(1):1523.

Shen H, Zhong M. Preparation and evaluation of selfmicroemulsifying drug delivery systems (SMEDDS) containing atorvastatin. J Pharm Pharmacol. 2006;58(9):1183-1191.

Shinoda K, Araki M, Sadaghiani A, Khan A, Lindman B. Lecithin-based microemulsions: phase behaviour and microstructure. J Phys Chem. 1991;95(2):989-993.

Yosra SRE, Magda AE, Ossama YA. Self-nanoemulsifying drug delivery systems of tamoxifen citrate: design and optimization. Int J Pharm. 2009;380(1-2):133-141.

Zhang P, Liu Y, Feng N, Xu J. Preparation and evaluation of self-microemulsifying drug delivery system of oridonin. Int $\mathrm{J}$ Pharm. 2008;355(1-2):269-276.

Received for publication on $25^{\text {th }}$ April 2017 Accepted for publication on $18^{\text {th }}$ October 2017 